\title{
Using a Comprehensive Third-Party Exam for ABET Student Outcome Assessment
}

\author{
Christopher Nitta \\ Department of Computer Science \\ University of California, Davis \\ Davis, CA, USA \\ cjnitta@ucdavis.edu
}

\author{
Kurt Eiselt \\ Department of Computer Science \\ University of California, Davis \\ Davis, CA, USA \\ eiselt@ucdavis.edu
}

\begin{abstract}
In anticipation of an $\mathrm{ABET}$ accreditation visit, our computer science department contracted with an independent external testing organization to perform an assessment of our students' proficiency in computer science. We used this external assessment to supplement our own internal assessment and have continued using since our site visit. In this paper, we talk about the comprehensive test, how it was administered, the steps we took to validate the results of the external assessment, and how we integrated the results into our ABET self-study report. We also explore insights we gained from the testing about our program and our students, as well as some of the limitations of the test.
\end{abstract}

\section{CCS CONCEPTS}

- Social and professional topics $\rightarrow$ Accreditation; Computational science and engineering education; Student assessment.

\section{KEYWORDS}

ABET, Accreditation, Student Assessment, CS2013

\section{ACM Reference Format:}

Christopher Nitta and Kurt Eiselt. 2021. Using a Comprehensive Third-Party Exam for ABET Student Outcome Assessment. In Proceedings of the 52nd ACM Technical Symposium on Computer Science Education (SIGCSE '21), March 13-20, 2021, Virtual Event, USA. ACM, New York, NY, USA, 6 pages. https://doi.org/10.1145/3408877.3432529

\section{INTRODUCTION}

In its general criteria for accreditation, ABET (formerly the Accreditation Board for Engineering and Technology, now officially just $\mathrm{ABET}$ ) states that a computer science program applying for accreditation "must have documented student outcomes that prepare graduates to attain the program educational objectives. There must be a documented and effective process for the periodic review and revision of these student outcomes." [3] In its Self-Study Questionnaire Template, ABET offers suggestions for the instruments that might be used to gather the necessary data: responses to in-class exam questions, homework assignments, and senior projects, to

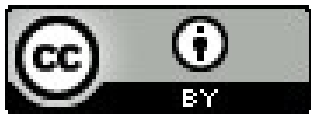

This work is licensed under a Creative Commons Attribution International 4.0 License. SIGCSE '21, March 13-20, 2021, Virtual Event, USA. (C) 2020 Copyright held by the owner/author(s). ACM ISBN 978-1-4503-8062-1/21/03.

https://doi.org/10.1145/3408877.3432529 name a few. [2] When the people who create the assessment instruments are the same people who evaluate the results, however, we end up asking what can we really conclude from the results about what our students have learned? [6] For example, are we asking the right questions on exams and performing accurate and objective evaluations, or are our assessments possibly less rigorous, and consequently less useful, when evaluating student outcomes? To address this question, and to provide some external validation of the claims we make about our students' learning, our department employed the services of an external testing organization to offer our students a comprehensive and independent assessment of their learning. To be fair, ABET does not expect a department to employ a nationally-normed exam as part of its accreditation effort, but they do not discourage the practice. The remainder of this paper is organized as follows. Section 2 provides a background on the exam and the institution's programs, followed by a description of how the exam was proctored in Section 3. Section 4 describes the ABET student outcome assessment methodology and results. A description of how the test results can be extended to a program level analysis with use of course grade information is presented in Section 5. Section 6 provides an overall discussion with conclusions and future work in Section 7.

\section{BACKGROUND}

We discovered that the Institute for Certification of Computing Professionals (ICCP) offered a comprehensive Computer Science examination that we believed would provide us with a good thirdparty evaluation of our student's preparedness. ICCP was founded in 1973 and is an internationally recognized certification program for professionals in the information, communications and technology industry [5]. The ICCP CS2013 exam was developed to assess the ACM and IEEE-Computer Society sponsored comprehensive Computer Science Curricula 2013 (CS2013) using a computerized three-option multiple choice exam. The ICCP CS2013 exam tests 15 knowledge areas in varying depth with a total of 166 questions representing the 166 hours of knowledge from the ACM/IEEE CS2013 [7]. Table 1 shows the ICCP exam knowledge areas, the associated code, and the number of questions in the particular area for the version of the exam our students took. In addition to the knowledge areas, ICCP provides a mapping of each question to its ABET Computing Accreditation Commission (CAC) student outcome criteria. This allowed us to calculate an overall estimate of the performance of our students within many of the CAC a $\mathrm{k}$ criterion (it should be noted that ABET CAC has moved to a 1 - 5 student outcomes with a 6th for programs named Computer Science in their new cycle). Table 2 lists the CAC student outcomes 
Table 1: ICCP CS Exam Knowledge Areas

\begin{tabular}{|c|l|c|}
\hline Code & \multicolumn{1}{|c|}{ Knowledge Area } & \# Q's \\
\hline AL & Algorithms & 22 \\
\hline CN & Computational Science & 2 \\
\hline DS & Discrete Structures & 36 \\
\hline GV & Graphics and Visual Computing & 2 \\
\hline HCI & Human Computer Interaction & 4 \\
\hline IAS & Information Assurance and Security & 3 \\
\hline IM & Information Management & 1 \\
\hline NC & Networking and Communications & 4 \\
\hline OS & Operating Systems & 4 \\
\hline PD & Parallel and Distributed Computing & 4 \\
\hline PL & Programming Languages & 8 \\
\hline SDF & Software Development Fundamentals & 40 \\
\hline SE & Software Engineering & 7 \\
\hline SF & Systems Fundamentals & 18 \\
\hline SP & Social Issues and Professional Practice & 11 \\
\hline
\end{tabular}

$\mathrm{a}-\mathrm{k}$ that had been in place until the $2019-2020$ evaluation year. Table 3 lists the CAC student outcomes $1-6$ that have been in place since 2019. Our university offers two majors overseen by our department: Computer Science and Engineering (CSE) and Computer Science (CS). The CSE program is ABET accredited, while the CS program is not. The CSE students are required to take a two term Senior Design course (ECS 193A/B) as part of their degree requirements, where the CS students do not, although some CS students opt to take it as one of their electives. Table 4 shows a list of course numbers and course titles for the core CS courses required for the CSE students.

\section{ICCP EXAMINATION PROCTORING}

The exam was offered to students of the ECS 193B course, in the second week of the course's second term in 2018 and 2019. Taking the exam was not mandated by the ECS 193B instructor but was encouraged. The exam was held from $6 \mathrm{P}-9 \mathrm{P}$ at night, and dinner was provided for the students that took the exam. Each year 40 students took the exam, $47 \%$ of the 86 students enrolled in ECS 193B in 2018 and $51 \%$ of the 78 students enrolled in ECS 193B in 2019. The exam was planned to be mandated in 2020, but due to COVID19 the exam was offered purely online over a one-week period. In $2020,24 \%$ of the 88 students enrolled in ECS 193B completed both sections of the exam. Since the exam was not mandatory but voluntary, there was a concern that the pool of test takers would not be a representative sample due to selection bias. Logically this concern would seem to be merited as students that are willing to volunteer to take a multi-hour test are more likely better students. This concern was one of the reasons that we had initially planned to mandate the exam in 2020 . In order to determine if the test takers were a representative sample of the Senior Design students, we looked at the course grade distributions. At our institution we use letter grading of $\mathrm{A}$ through $\mathrm{F}$ that is common in the United States. An A letter grade has an equivalent 4.0 grade points and $\mathrm{F}$ is equivalent to 0.0 . Table 5 shows the letter grade definitions and associated grade points. Figure 1 shows the grade distribution for
Table 2: ABET CAC Student Outcomes a-k for pre-2019

\begin{tabular}{|c|c|}
\hline Outcome & Statement \\
\hline $\mathrm{a}$ & $\begin{array}{l}\text { An ability to apply knowledge of computing and math- } \\
\text { ematics appropriate to the program's student out- } \\
\text { comes and to the discipline }\end{array}$ \\
\hline $\mathrm{b}$ & $\begin{array}{l}\text { An ability to analyze a problem, and identify and de- } \\
\text { fine the computing requirements appropriate to its } \\
\text { solution }\end{array}$ \\
\hline $\mathrm{c}$ & $\begin{array}{l}\text { An ability to design, implement, and evaluate a } \\
\text { computer-based system, process, component, or pro- } \\
\text { gram to meet desired needs }\end{array}$ \\
\hline $\mathrm{d}$ & $\begin{array}{l}\text { An ability to function effectively on teams to accom- } \\
\text { plish a common goal }\end{array}$ \\
\hline $\mathrm{e}$ & $\begin{array}{l}\text { An understanding of professional, ethical, legal, secu- } \\
\text { rity and social issues and responsibilities }\end{array}$ \\
\hline $\mathrm{f}$ & $\begin{array}{l}\text { An ability to communicate effectively with a range of } \\
\text { audiences }\end{array}$ \\
\hline g & $\begin{array}{l}\text { An ability to analyze the local and global impact of } \\
\text { computing on individuals, organizations, and society }\end{array}$ \\
\hline $\mathrm{h}$ & $\begin{array}{l}\text { Recognition of the need for and an ability to engage } \\
\text { in continuing professional development }\end{array}$ \\
\hline i & $\begin{array}{l}\text { An ability to use current techniques, skills, and tools } \\
\text { necessary for computing practice. }\end{array}$ \\
\hline $\mathrm{j}$ & $\begin{array}{l}\text { An ability to apply mathematical foundations, algo- } \\
\text { rithmic principles, and computer science theory in the } \\
\text { modeling and design of computer-based systems in a } \\
\text { way that demonstrates comprehension of the tradeoffs } \\
\text { involved in design choices. }\end{array}$ \\
\hline $\mathrm{k}$ & $\begin{array}{l}\text { An ability to apply design and development principles } \\
\text { in the construction of software systems of varying } \\
\text { complexity. }\end{array}$ \\
\hline
\end{tabular}

Table 3: ABET CAC Student Outcomes 1-6 for $2019^{+}$

\begin{tabular}{|c|l|}
\hline Outcome & \multicolumn{1}{|c|}{ Statement } \\
\hline 1 & $\begin{array}{l}\text { Analyze a complex computing problem and to apply } \\
\text { principles of computing and other relevant disciplines } \\
\text { to identify solutions. }\end{array}$ \\
\hline 2 & $\begin{array}{l}\text { Design, implement, and evaluate a computing-based } \\
\text { solution to meet a given set of computing require- } \\
\text { ments in the context of the program's discipline. }\end{array}$ \\
\hline 3 & $\begin{array}{l}\text { Communicate effectively in a variety of professional } \\
\text { contexts. }\end{array}$ \\
\hline 4 & $\begin{array}{l}\text { Recognize professional responsibilities and make in- } \\
\text { formed judgments in computing practice based on } \\
\text { legal and ethical principles. }\end{array}$ \\
\hline 5 & $\begin{array}{l}\text { Function effectively as a member or leader of a team } \\
\text { engaged in activities appropriate to the program's } \\
\text { discipline. }\end{array}$ \\
\hline 6 & $\begin{array}{l}\text { Apply computer science theory and software devel- } \\
\text { opment fundamentals to produce computing-based } \\
\text { solutions. }\end{array}$ \\
\hline
\end{tabular}


Table 4: Core CS Course Numbers and Titles

\begin{tabular}{|l|l|}
\hline Course Number & \multicolumn{1}{|c|}{ Title } \\
\hline ECS 20 & Discrete Mathematics \\
\hline ECS 36A & Programming and Problem Solving \\
\hline ECS 36B & Software Development \& OOP \\
\hline ECS 36C & Data Structures \\
\hline ECS 50 & Computer Organization \\
\hline ECS 120 & Theory of Computation \\
\hline ECS $122 \mathrm{~A}$ & Algorithms \\
\hline ECS 132 & Probability and Statistical Modeling \\
\hline ECS $140 \mathrm{~A}$ & Programming Languages \\
\hline ECS 150 & Operating Systems \\
\hline ECS $152 \mathrm{~A}$ & Computer Networks \\
\hline ECS $154 \mathrm{~A}$ & Computer Architecture \\
\hline ECS 160 & Software Engineering \\
\hline ECS 188 & Ethics \\
\hline ECS $193 \mathrm{~A} / \mathrm{B}$ & Senior Design \\
\hline
\end{tabular}

Table 5: Letter Grade Definitions

\begin{tabular}{|c|c|l|}
\hline Grade & Points & Description \\
\hline A & 4.0 & Excellent \\
\hline B & 3.0 & Good \\
\hline C & 2.0 & Fair \\
\hline D & 1.0 & Barely Passing \\
\hline F & 0.0 & Not Passing \\
\hline
\end{tabular}

the Senior Design students classified as ICCP test takers, non-test takers and the entire class. In addition, both the overall Grade Point Average (GPA) and ECS GPA are provided. The boxes represent the first quartile, median and third quartile. The error bars show the range of grades, and the $\mathrm{X}$ marks the average of the grades. Students below 2.0 are not in good standing, that is why the min displayed is at 2.0. Their grade data did not show a significant difference between the test takers and the rest of the class. The average overall GPA for the test takers was 3.24 vs. 3.21 for non-test takers with an ECS GPA of 3.27 and 3.23 for test takers and non-test takers respectively. There was a very small effect size of 0.05 and 0.06 for the test takers overall and ECS GPAs. Given the results of the grade analysis we believe that the test takers are a good representation of the overall students in the course.

\section{ABET STUDENT OUTCOME ASSESSMENT}

In this section we describe the methodology used to create the ABET student outcome assessment and provide the results of the student attainment.

\subsection{Methodology}

ICCP provides the number of exam questions in each knowledge area and the associated ABET CAC student outcome $\mathrm{a}-\mathrm{k}$. In order to determine the attainment of each student outcome the scores from each knowledge area were weighed by the number of student outcome questions in that particular area. Once a percentage was calculated from the weighting, the student outcomes were classified
GPA Distributions ICCP Test Takers vs. Non-Takers

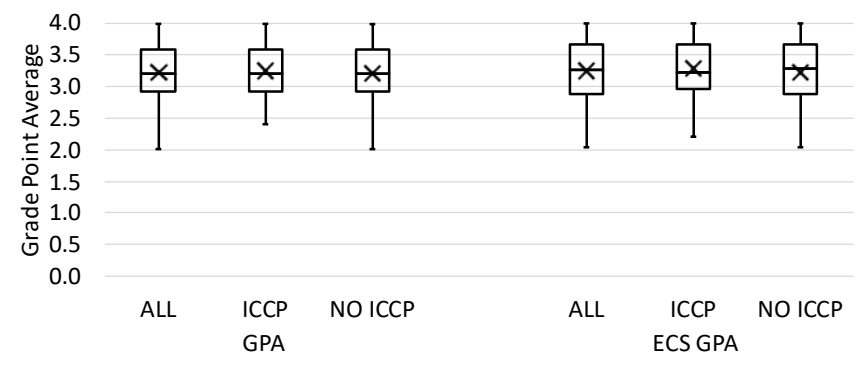

Figure 1: GPA Distributions for ICCP Test Takers and NonTest Takers of ECS 193B

into exceeds, meets, approaches, or does not approach the standard. The standard of meeting the outcomes was set to passing, which is $50 \%$ on the ICCP CS2013 exam, with exceeding the standard set at the honors level of $70 \%$. Those scoring at least $41.5 \%$ were considered to be approaching the standard, while those below $41.5 \%$ were considered to not be meeting or approaching the standard. The value of $41.5 \%$ threshold was chosen because it represented the midpoint between passing, and the expected score from purely guessing on the multiple choice exam composed completely of three-option questions. Moving forward from the site visit, it was necessary to develop a methodology to assess the students on the 2019 CAC student outcomes $1-6$. Unfortunately, at this time ICCP does not provide the questions classified as student outcomes 1 -6 , so we chose to assign them as student outcome $1-6$ using the old a - k classification and employing a methodology similar to that described by ABET Engineering Area Delegation for the Engineering Accreditation Commission (EAC) in [1].

\subsection{Assessment Results}

Overall the students at our institution performed quite well on the ICCP exam. Figure 2 shows the assessment of the ICCP exam performance for nine of the CAC student outcomes classified into exceeds, meets, approaches, or does not approach the standard. The students on average met or exceeded the particular criteria $84 \%$ of the time. Unfortunately, some of the criteria may have only had a few questions leading to fairly polarized results such as CAC student outcome b. CAC student outcome g (An ability to analyze the local and global impact of computing on individuals, organizations, and society) shows one point about which we have been concerned. As we will discuss in the next section our Ethics course ECS 188 is not required for all students but we believe it is related to outcome g. We believe that requiring the course for both majors would improve upon this particular student outcome. Figure 3 shows the assessment of the ICCP exam performance for the six CAC student outcomes classified into exceeds, meets, approaches, or does not approach the standard. Similarly, the students performed quite well since the results were combinations of the Figure 2 results. The results of the student outcome assessments done prior to our ABET Self-Study Report (SSR) submission were included in the SSR (essentially Figure 2 with the earlier exam results). The exam results not only allowed for the vast majority of student outcomes to be assessed with a single exam but also allowed us to compare our 


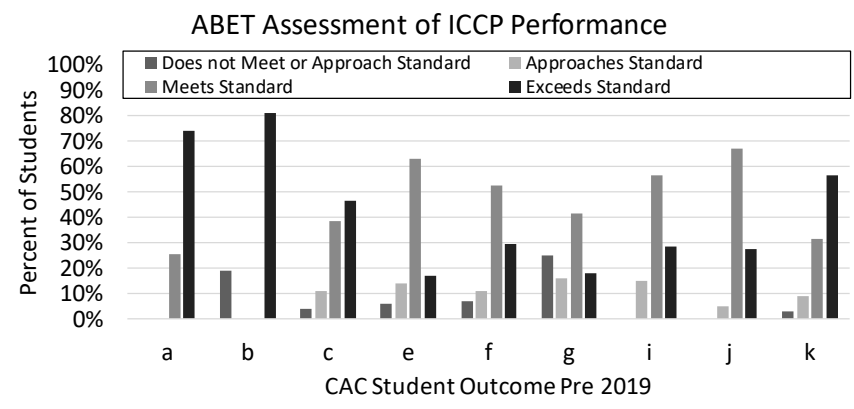

Figure 2: ABET Assessment of ICCP Performance Pre 2019 Outcomes

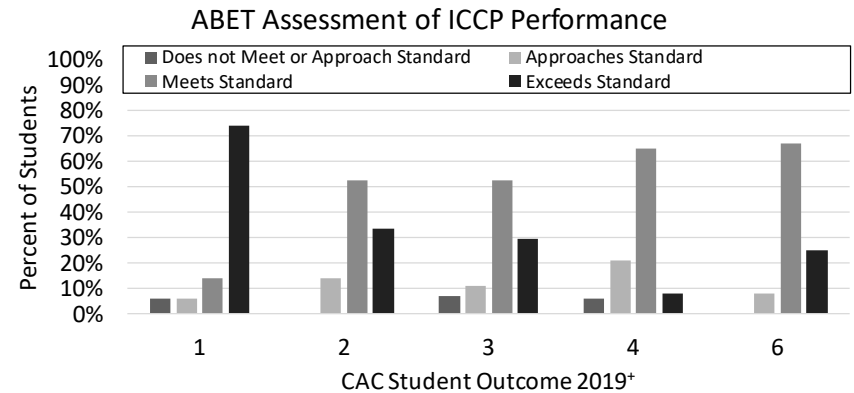

Figure 3: ABET Assessment of ICCP Performance Post 2019 Outcomes

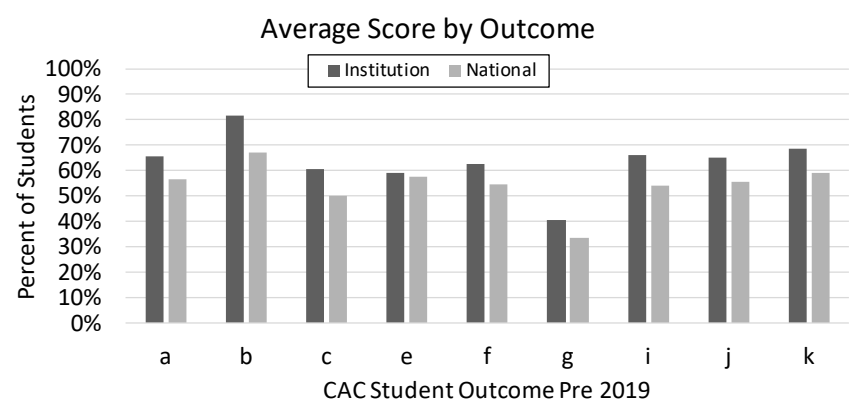

Figure 4: Average ICCP Score on Pre 2019 Outcomes

students to the national average of the test takers. Figure 4 shows the comparison at the institution level between our institution and the national average (a similar figure was included in our SSR). Given the results, we were able to identify knowledge areas in which we would like to improve and provide planned actions in order to improve performance. The ability to assess the performance of the students, suggest actions to improve, implement those actions, and then assess again allows for closing of the continuous improvement loop. ABET looks for programs to demonstrate that they have closed the loop.

\section{PROGRAM ASSESSMENT}

Given the external exam results, we were interested in determining if student performance in our courses was correlated with performance on the ICCP knowledge area. Looking at the detailed knowledge area information we were able develop a set of courses that we believed should correlate with the particular ICCP knowledge area. As stated previously, at our institution we use letter grading of A through $\mathrm{F}$ that is common in the United States. The numerical grade points were used in the correlation of course grade with ICCP exam knowledge area score. When considering the students' grades for the analysis, a question arose: what should be done if the student had not taken the course yet? Should the grade be considered zero, should the sample be ignored altogether, or should the average over the other classes be used? There is useful information in the fact that the student has not taken the course, so we did not want to ignore that. In addition to the question about missing course grades, another discussion arose about handling students that took the course from "easy" vs. "hard" instructors. Should the grade points or the percentile of the student be used? Using the percentile approach allows for easy vs. hard fought A's to be distinguished from one another. Unfortunately, exact student percentiles could not be determined for each course since only course grades were available. However, the range could be bounded since all of the assigned grades for courses at our institution were available. The middle point of the grade range was chosen as a representation of the percentile. The discussion of calculating the percentile for each student led to yet another question: how should student's percentile be calculated when they took the course at another institution, and the complete grade data for that particular course is not available? Should those students be excluded, should the percentile be calculated as if the course was taken at our institution, or should the average of the student's percentiles be used as an alternative? We ultimately settled on running all of the analyses and decided to provide the range of performance using the different methodologies. Using the range of methodologies, we calculated p-Values for each knowledge area and corresponding course(s). Table 6 shows the algorithm designation and a brief description of how any missing grade information was handled. The AG and AP algorithms used the student's Grade Point Average (GPA) and average percentile respectively for students that did not take the course or did not have percentile information available. The CG and CP algorithms excluded students from the correlation if the information was not available. The FP algorithm attempted to "fake" a percentile by converting the grades taken externally to an equivalent percentile if the course had been taken at our institution. The ZG and ZP algorithms essentially assigned the student an $\mathrm{F}$ grade or 0 percentile if the course had not been completed. Figure 5 shows the geomean of the various algorithms used. Overall, we found that using student percentile with an average percentile standing in for not taking the course (algorithm AP) provided the best correlations on average. Figure 6 shows the p-Value ranges with the ICCP knowledge area and the group of related courses for that knowledge area. The dot is the p-Value using the AP methodology, and the error bars show the range of the other methodologies. Not surprisingly, we found the strongest correlation between overall ICCP test score and overall ECS course performance. You will notice that all are able to reject 
Table 6: Correlation Algorithm Description

\begin{tabular}{|c|l|}
\hline Algorithm & \multicolumn{1}{c|}{ Description } \\
\hline AG & GPA for missing grade \\
\hline AP & Average percentile for missing percentile \\
\hline CG & Course grades only used \\
\hline CP & Percentiles only for courses at institution \\
\hline FP & Percentiles for equivalent grade \\
\hline ZG & "F" grade for missing course grades \\
\hline ZP & 0 Percentile for missing course grades \\
\hline
\end{tabular}

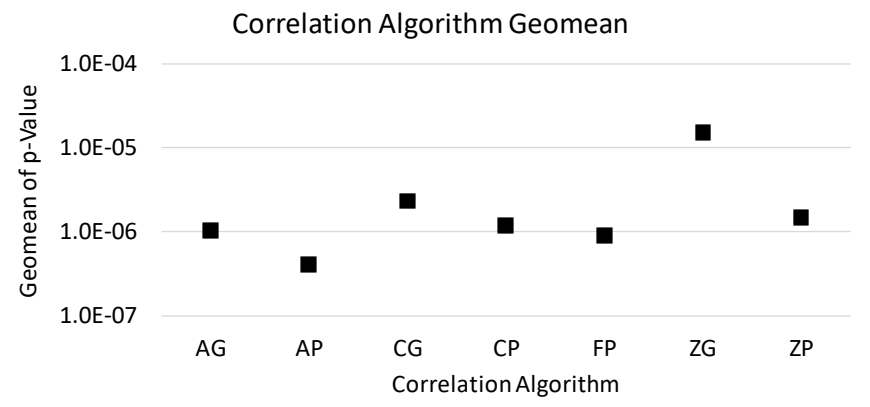

Figure 5: Geomean of p-Value for Algorithms

the null hypothesis, though the SP (Social Issues and Professional Practice) had the weakest correlation. This is primarily due to the fact that ECS 188 Ethics is required for the CSE students, but not the CS students. Since the class sizes of ECS 188 are kept to 24 students, it is challenging for the CS students to take ECS 188. One may think that there should be strong correlations between any course and the score on a particular knowledge area; however, Figure 7 shows that there is not a strong correlation between other courses and the SP knowledge area. Another reason that the correlation may be weak is that there is a relatively tight distribution of grades in the ECS 188 course. Figure 8 shows the distribution of course grades in the CSE curriculum over the past 5 years. The boxes represent the first quartile, median and third quartile. The error bars show the range of grades (all have A through F), and the X marks the average of the grades. One should take note that ECS 188 has the highest grade average of 3.52 compared to the overall CS grade average of 2.89 . As discussed previously since CAC student outcome $\mathrm{g}$ appeared to be one of the worst outcomes for attainment, we are investigating how we might provide ECS 188 to all of our students, and how we might provide a larger distribution of grades within the course.

\section{DISCUSSION}

The use of the ICCP CS2013 exam was valuable in assessing the performance of our students near the end of their tenure in our programs. Using the PDF summaries generated by the exam for each student provided valuable information about each individual student's performance that we were then able to correlate with the student's course performance. The PDF summaries while useful, provide only aggregate scores per knowledge area and omit detailed scoring on each particular question (or even the question text). More granular results in the student PDF summaries, or a list of
p-Value Related Course Performance to ICCP Knowledge Area Performance

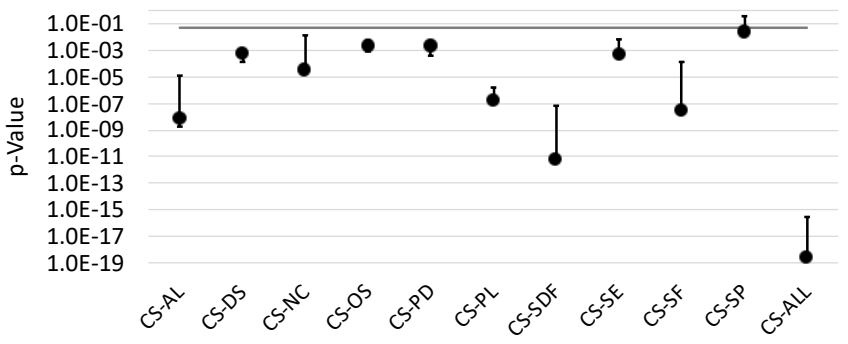

Figure 6: Related Course Performance to ICCP Knowledge Area Performance

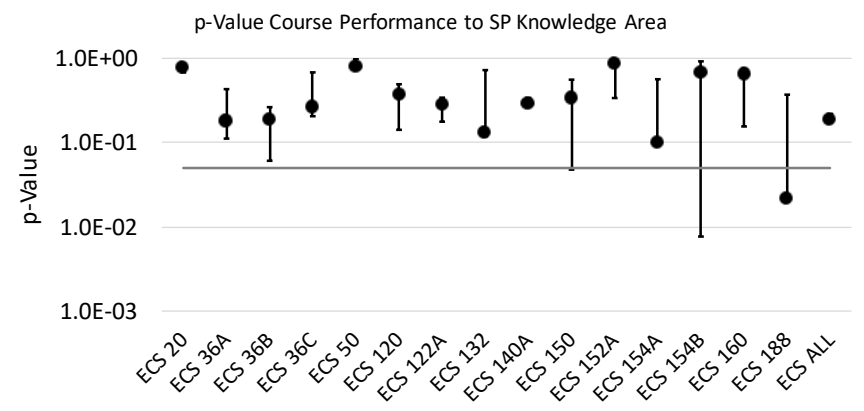

Figure 7: Course Performance to ICCP SP Knowledge Area Performance

GPA Distribution By Course

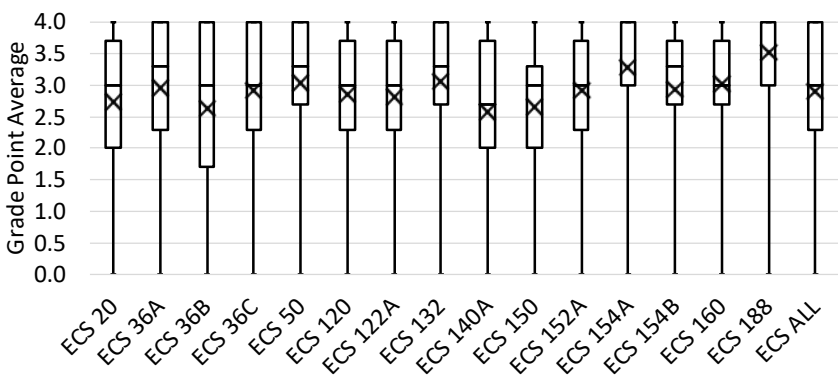

Figure 8: GPA Distribution by Course

commonly missed questions for the institution would be invaluable for improving a program. Even with the available information from the ICCP exam we were able to create a metric for many of the CAC student outcome assessments. If the ICCP PDF summary results were to be updated to also provide aggregate ABET CAC student outcome scores, or if the final ICCP institution report provided aggregate numbers of student performance on each of the new CAC student outcomes classified in their Fail, Pass, Honors, and Expert classifications, the exam would become extremely valuable to ABET accredited programs. Considering that the Computing Curricula 2020 draft was recently released (see [4]), we hope that ICCP will update the exam once the curricula has been finalized. The results of the ICCP exam have provided valuable insight into 
our program and have raised new questions we would like to answer in order to continue improving our program. An example of an insight is the concern with ECS 188, and how we might improve our programs by requiring it for all students.

\section{CONCLUSIONS AND FUTURE WORK}

The ICCP exam is remarkably easy to administer, and the time between giving the exam and receiving the results from ICCP is relatively brief. Even with COVID-19 we were able to administer the exam using connection to remote machines provided by ICCP. The information we received from the exam provided some validation of what we already believed were our strengths, and also confirmed some areas in which we knew we were weaker than we should be. While there was much to be gleaned from the exam results, ICCP was unable to give us everything we asked for; we hope that will change for the better in the future. Our correlation of the exam results to student GPAs led to valuable insights about our program and our students. We will be offering the ICCP exam again in the immediate future, and we will continue to pursue answers to the questions that our accreditation efforts have raised. We believe that removing the self-selection of the test takers could help to answer some of the questions raised and are looking into requiring the ECS 193B students to take the ICCP exam. Will we see a removal of the bias once every ECS 193B student is required to take the ICCP exam?

\section{ACKNOWLEDGMENTS}

We would like the thank the 101 students that volunteered to take the ICCP exam who will need to remain nameless.

\section{REFERENCES}

[1] ABET. 2018. C3 C5 mapping SEC 1-13-2018. Online. Retrieved November 10, 2020 from https://www.abet.org/wp-content/uploads/2018/03/C3_C5_mapping_ SEC_1-13-2018.pdf

[2] ABET. 2018. Computing Accreditation Commission: Self-Study Questionnaire: Template for the Computing Self-Study. Online. Retrieved November 10, 2020 from https://www.abet.org/accreditation/get-accredited/ accreditation-step-by-step/self-study-report/dual-templates-for-cac/

[3] ABET. 2018. Criteria for Accrediting Computing Programs, 2018-2019: General Criterion 3. Student Outcomes. Online. Retrieved November 10, 2020 from https://www.abet.org/accreditation/accreditation-criteria/ criteria-for-accrediting-computing-programs-2018-2019/\#GC3

[4] ACM/IEEE. 2020. Computer Curricula 2020 CC2020 Paradigms for Future Computing Curricula. Online. https://drive.google.com/file/d/ 1LPbxATWYSQlFJEB0ejDlsj1P_tVH0TLm/view?usp=sharing

[5] ICCP. 2018. About the ICCP. Online. Retrieved November 10, 2020 from https: //iccp.org/about-us---old.html

[6] Terry Linkletter and John Whitehouse. 2013. How Do We Know Our Students Have Learned the BS Outcomes? An Overview of Assessment, Accreditation, the Model Curricula, and Certification - in Information Systems and in Computer Science. F. Comput. Sci. Coll. 29, 1 (Oct. 2013), 96-97.

[7] James W. McGuffee, E. Kent Palmer, and Indira R. Guzman. 2016. Assessing the Tier-1 Core Learning Outcomes of CS2013. In Proceedings of the 47th ACM Technical Symposium on Computing Science Education (Memphis, Tennessee, USA) (SIGCSE '16). Association for Computing Machinery, New York, NY, USA, 485-489. https://doi.org/10.1145/2839509.2844613 